\title{
Are Oxygen and Sulfur Atoms Structurally Equivalent in Organic Crystals?
}

\author{
Mérina K. Corpinot, ${ }^{\dagger, \S}$ Rui Guo, ${ }^{\dagger, \S}$ Derek A. Tocher, ${ }^{\dagger}$ Asma B. M. Buanz, ${ }^{\ddagger}$ Simon Gaisford, ${ }^{\ddagger}$ \\ Sarah L. Price, ${ }^{\dagger}$ and Dejan-Krešimir Bučar*, ${ }^{*}+0$ \\ ${ }^{\dagger}$ Department of Chemistry, University College London, 20 Gordon Street, London WC1H 0AJ, U.K. \\ ${ }^{\ddagger}$ UCL School of Pharmacy, University College London, 29-39 Brunswick Square, London WC1N 1AX, U.K.
}

Supporting Information

ABSTRACT: New guidelines for the design of structurally equivalent molecular crystals were derived from structural analyses of new cocrystals and polymorphs of saccharin and thiosaccharin, aided by a computational study. The study shows that isostructural crystals may be obtained through an exchange of $>\mathrm{C}=\mathrm{O}$ with $>\mathrm{C}=\mathrm{S}$ in the molecular components of the solids, but only if the exchanged atom is not involved in hydrogen bonding.

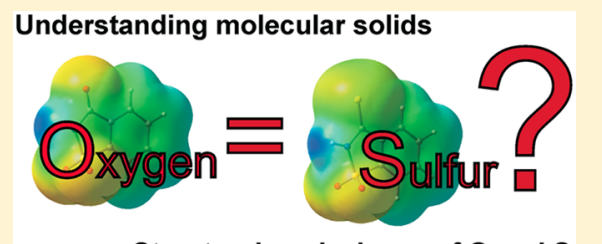

Structural equivalence of $O$ and $S$ in molecular crystals

\section{INTRODUCTION}

Organic crystals are the main constituents of medicines, ${ }^{1,2}$ molecular semiconductors, ${ }^{3,4}$ pigments, ${ }^{5,6}$ and other relevant materials that have a profound impact on modern society and our quality of life. The development and marketing of such specialty chemicals often demands decades of dedicated research, ${ }^{7}$ with the fine-tuning of their solid-state properties representing a critical part of the development process. $^{2}$ Such fine-tuning involves the strategic rearrangement of molecules in their crystal lattice ${ }^{8,9}$ and requires a detailed understanding of the self-assembly of molecules into crystal structures. ${ }^{10}$ With this (and the growing interest in organic solids) in mind, a great number of crystallographic studies in the past 2 decades focused on the identification of noncovalent interactions that can be reliably utilized to design and construct crystalline fitfor-purpose materials. ${ }^{11}$ These efforts soon led to the formulation of reliable strategies for the construction of metal-organic frameworks with desired crystal structures and properties, $^{12}$ exploiting coordinate bonds. This in turn, elevated metal-organic materials from objects of curiosity in inorganic chemistry ${ }^{13}$ to a cornerstone of contemporary materials science in less than 2 decades. $^{14,15}$ Progress in the design of crystal structures based entirely on organic molecules, on the other hand, has not been as fast or as remarkable. ${ }^{16-18}$

The slower development of organic crystal structure design is certainly not to be attributed to a lack of effort from the crystal engineering community. On the contrary, a survey of the literature shows a rapidly growing number of crystallographic $^{11,19}$ and computational studies ${ }^{20-22}$ of molecular crystals, wherein the molecules are held together by weak noncovalent interactions, such as hydrogen and halogen bonds. In comparison to coordinate forces, the weaker strength and directionality of hydrogen and halogen bonds impose greater challenges in predicting the outcome of a crystallization experiment, even for small and rigid molecules. ${ }^{16,23-25}$
Significant progress has been made in predicting zero-, oneand two-dimensional supramolecular assemblies within crystals based on up to two distinct molecules and involving up to two strong hydrogen- or halogen-bond donors and acceptors. ${ }^{26-29}$ However, predicting the crystal packing of such molecular arrays without the use of computational crystal structure prediction still remains unmanageable. ${ }^{17,18,30}$

Overall, our ability to foresee the outcome of short-range molecular assembly, and thus to rationally fine-tune solid-state properties, is predicated upon a small number of guidelines and principles, derived from extensive crystallographic studies, which mainly concerned the interchangeability of atoms and functional groups (e.g., $\mathrm{CH}_{3} / \mathrm{Cl}^{31-35} \mathrm{Cl} / \mathrm{Br},{ }^{34,36-38} \mathrm{Br} / \mathrm{I},{ }^{34,37,38}$ $\mathrm{O} / \mathrm{S}^{34}$ ) in single-component molecular crystals, and synthon hierarchies for a narrow range of functional groups (e.g., alcohols $^{26-28}$ and carboxylic acids, ${ }^{39,40} \mathrm{~N}$-based aromatic heterocyclic compounds, ${ }^{29,39,40}$ oximes, ${ }^{41}$ and I-/Br-based halogen donors ${ }^{42-44}$ ) in multicomponent molecular crystals (i.e., cocrystals). The development of more robust and versatile synthetic strategies in crystal engineering, however, requires the establishment of more comprehensive guidelines for the design of crystal structures through a better understanding of how molecules assemble in the solid state. ${ }^{11}$

One area from which further crystal engineering guidelines may be derived is the study of isostructurality, ${ }^{45}$ i.e., the ability of distinct molecules to form crystals with almost identical packing arrangements in molecular crystals. ${ }^{46}$ More than 60 years ago, Kitaigorodskii's seminal studies of molecular solids and isostructurality led to the understanding that crystal structures can remain virtually unchanged if particular atoms or functional groups are exchanged in the constituent molecule. $^{34}$ To be specific, it was shown that interchanging

Received: November 17, 2016

Published: December 1, 2016 
$\mathrm{Cl}, \mathrm{Br}$, and $\mathrm{I}$ halogen atoms in a molecule frequently results in the formation of isomorphous crystals ${ }^{34}$ - that is, solids with identical structures and unit-cell parameters and of the same symmetry ${ }^{47}$ (and therefore also the same morphology). It was further suggested that exchanges of $\mathrm{O}$ and $\mathrm{S}$ atoms, as well replacements of $\mathrm{C}$ with $\mathrm{Si}, \mathrm{Ge}, \mathrm{Sn}$, and $\mathrm{Pb}$, support isomorphic crystal growth. $^{34}$ These observations lead to the idea that approximate geometrical similarity and volume relationships are decisive in the growth of isostructural molecular crystals, while the chemical features of atoms may have little effect on molecular interactions and thus crystal packing. ${ }^{34}$

More than 2 decades later, however, it was observed that directional noncovalent interactions (e.g., $\mathrm{Cl} \cdots \mathrm{Cl}$ halogen bonds) might play a considerable role in the shaping of isostructural crystals. ${ }^{48-50}$ To our knowledge, the latter hypothesis was never strengthened by further systematic structural studies. With this in mind, we resolved to scrutinize the purported structural equivalence of $\mathrm{O}$ and $\mathrm{S}$ atoms in molecular crystals and aimed to determine to what extent noncovalent interactions, particularly hydrogen bonding, interfere with the formation of isostructural multicomponent crystals through $\mathrm{O} / \mathrm{S}$ atom replacements. Surprisingly, no structural studies that aim to understand the effects of chalcogen exchange on the solid-state structure of these emerging materials have so far been reported-this is despite the growing interest in fine-tuning of molecular and bulk properties through the exchange of chalcogens in molecular electronics, ${ }^{51-54}$ pharmaceuticals, ${ }^{55}$ light emitters, ${ }^{56} \mathrm{COFs},{ }^{57}$ zeolites, $^{58}$ and anion receptors. ${ }^{59}$

\section{RESULTS AND DISCUSSION}

Here, we present a crystallographic analysis of cocrystals and salts containing saccharin (sac) and the structurally related compound thiosaccharin (tsac) (Figure 1). The analysis reveals a)

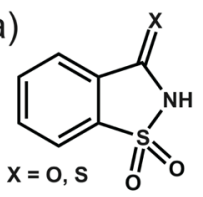

b)

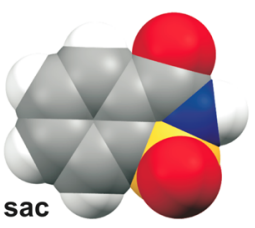

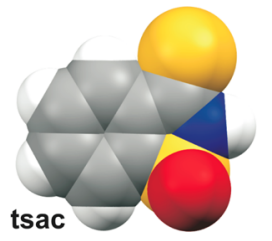

Figure 1. (a) Chemical structures of sac $(X=O)$ and tsac $(X=S)$ and (b) space-fill representation of sac and tsac, highlighting their similarity in size and shape.

that $\mathrm{O} / \mathrm{S}$ exchange in the carbonyl group of sac results in the formation of isostructural ${ }^{46}$ (i.e., structurally similar) and isomorphous $^{47}$ (i.e., matching) tsac cocrystals only when sac molecules are not involved in hydrogen bonding via the $\mathrm{O}$ (carbonyl) atom in the corresponding sac crystal structure. The sensitivity of the hydrogen-bond patterns to $\mathrm{O} / \mathrm{S}$ exchange is further examined in a related computational study on the previously known, discovered in this study, and other putative polymorphs of sac and tsac. The computational study shows that $\mathrm{O} / \mathrm{S}$ exchange significantly changes the relative stabilities of sac and tsac crystal structures. The results of the crystallographic and computational analyses thus suggest additional guidelines for the design of isostructural molecular crystals involving the chalcogens-guidelines that will potentially improve our capacity to refine the properties of solids relevant to healthcare, energetic materials, and electronic devices.
The first part of our study involves a structural analysis of multicomponent solids combining sac and tsac with a series of pharmaceutically relevant cocrystal/salt formers, viz., 2-aminobenzamide $(\mathrm{ab})$, carbamazepine $(\mathrm{cbz})$, dihydrocarbamazepine (dhc), 2-fluorobenzamide (fba), haloperidol (hal), quinine (qui), sildenafil (sil), and theophylline (thp). The crystal structures of some of these salts or cocrystals have been reported elsewhere and were consequently obtained from the Cambridge Structural Database ${ }^{60}$ (CSD): (sac) $\cdot(\mathrm{cbz})$ (CSD refcode $\left.\mathrm{UNEZAO}^{61}\right),(\mathrm{sac}) \cdot(\mathrm{dhc})\left(\mathrm{CSD}\right.$ refcode OTESEM ${ }^{62}$ ), $(\mathrm{sac})^{-} \cdot(\mathrm{H}-\mathrm{hal})^{+}$(form I, CSD refcode YANMUW $\left.{ }^{63}\right),(\mathrm{sac})^{-}$. $(\mathrm{H}-\mathrm{hal})^{+}$(form II, CSD refcode YANMUW01 $\left.{ }^{64}\right)$, (sac) $)^{-} \cdot(\mathrm{H}-$ qui $^{+}\left(\mathrm{CSD}\right.$ refcode YANNIL $\left.{ }^{63}\right),(\mathrm{sac})^{-} \cdot(\mathrm{H}-\mathrm{sil})$ (CSD refcode QEKWEJ $^{65}$ ) and (sac).(thp) (CSD refcode XOBCUN ${ }^{66}$ ). The remaining cocrystals and salts were prepared and structurally characterized in the course of the present study: $(\mathrm{sac})^{-} \cdot(\mathrm{H}-$ $\mathrm{ab})^{+},(\mathrm{sac}) \cdot(\mathrm{fba}),(\mathrm{tsac})^{-} \cdot(\mathrm{H}-\mathrm{ab})^{+},(\mathrm{tsac}) \cdot(\mathrm{cbz}),(\mathrm{tsac}) \cdot(\mathrm{dhc})$, (tsac) $\cdot(\mathrm{fba}),(\mathrm{tsac})^{-} \cdot(\mathrm{H}-\mathrm{hal})^{+},(\mathrm{tsac})^{-} \cdot(\mathrm{H}-\mathrm{qui})^{+},(\mathrm{tsac})^{-} \cdot(\mathrm{H}-\mathrm{sil})$, and $(\mathrm{tsac})_{2} \cdot(\text { thp })_{2} \cdot\left(\mathrm{CH}_{3} \mathrm{NO}_{2}\right)$. All solids were synthesized by liquid-assisted grinding and characterized by single-crystal and powder X-ray diffraction (SCXRD and PXRD, respectively), attenuated total reflectance infrared spectroscopy (ATR-IR), and differential scanning calorimetry (DSC). Details concerning the characterization of the reported solids are given in the Supporting Information (SI) document.

The structural equivalence of $\mathrm{O}$ and $\mathrm{S}$ in the multicomponent crystals of sac and tsac was evaluated through an attempt to prepare isostructural multicomponent crystals. It was reasoned that if an $\mathrm{O} / \mathrm{S}$ exchange allows the formation of such similar or matching solids, $\mathrm{O}$ and $\mathrm{S}$ atoms could be considered equivalent in molecular crystals. The isostructurality of the sac and tsac crystal forms was assessed by a combination of crystal-packing (including hydrogen-bond pattern) analyses and crystal-packing-similarity calculations (i.e., geometric analyses of molecular clusters using distance constraints to represent molecular packing ${ }^{67}$ ) as implemented in Mercury CSD $3.8^{68}$ (see SI). ${ }^{69} \mathrm{~A} \mathrm{sac} / \mathrm{tsac}$ pair of solids were regarded as isostructural if (1) more than 10 molecules in the two molecular clusters comprised of 30 molecules that represent the crystal structure ${ }^{67}$ were successfully matched and (2) if the two solids display intermolecular interactions involving the same functional groups. Further powder pattern analyses (using Mercury CSD $3.8^{68,70}$ ) and the calculations of the unit-cell similarity indexes ${ }^{68,70}$ were performed to evaluate the extent of the structural similarity of two isostructural sac/tsac crystal forms (see SI). A pair of sac/tsac solids was classified as isomorphous if (1) the crystal-packing-similarity calculations revealed that all 30 molecules in the compared clusters matched in the sac/tsac clusters and (2) the sac/tsac solids score a unitcell similarity index close to 0 and a powder pattern similarity of (or higher than) 0.99 (see SI).

The analysis of packing features and packing similarity calculations of the analyzed solids revealed that four out of eight sac/tsac pairs of solids containing the same coformer were isostructural or isomorphous. Specifically, the sac and tsac solids involving $\mathrm{cbz}$, dhc, and sil were isostructural, while the structure based on the qui salt former was isomorphous (Table 1 and Figure 2). On the other hand, the tsac solids containing $\mathrm{ab}$, fba, hal, and thp were neither similar nor matching with their sac analogues (Figure 2 and Table 1). Notably, a common feature of the structurally distinct pairs of sac/tsac solids was the involvement of the $\mathrm{O}$ (carbonyl) atom of sac in hydrogen bonding. The isostructural and isomorphous pairs of solids, on 
Table 1. Summary of the Analysis of Crystal-Packing Features and Crystal-Packing-Similarity Calculations ${ }^{a}$

\begin{tabular}{|c|c|c|c|c|c|c|c|}
\hline $\begin{array}{l}\text { coformer in saccharin-based } \\
\text { crystal structure }\end{array}$ & $\begin{array}{l}\text { is the exchanged } \mathrm{O} \text { in- } \\
\text { volved in } \\
\text { hydrogen bonding? }\end{array}$ & $\begin{array}{c}\text { identical hydrogen } \\
\text { bonding in tsac } \\
\text { salt/cocrystal? }\end{array}$ & $\begin{array}{l}\text { crystal packing } \\
\text { similarity of } \\
\text { sac/tsac solids }\end{array}$ & $N / 30$ & $\begin{array}{l}\mathrm{rms} \\
(\AA)^{*}\end{array}$ & $\Pi$ & $\begin{array}{l}\text { PXRD pattern } \\
\text { similarity } \\
\text { score }\end{array}$ \\
\hline 2-aminobenzamide (ab) & $\checkmark$ & $x$ & none & 8 & 2.318 & 0.032 & 0.923 \\
\hline carbamazepine (cbz) & $x$ & $\checkmark$ & isostructural & 14 & 2.390 & 0.040 & 0.948 \\
\hline dihydrocarbamazepine (dhc) & $x$ & $\checkmark$ & isostructural & 13 & 1.938 & 0.344 & 0.954 \\
\hline 2-fluorobenzamide (fba) & $\checkmark$ & $x$ & none & 3 & 0.578 & 0.132 & 0.946 \\
\hline haloperidol (hal) (form I) & $\checkmark$ & $x$ & none & 1 & 0.819 & 0.354 & 0.913 \\
\hline haloperidol (hal) (form II) & $\checkmark$ & $x$ & none & 1 & 0.953 & 0.236 & 0.895 \\
\hline quinine (qui) & $x$ & $\checkmark$ & isomorphous & 30 & 0.325 & 0.023 & 0.990 \\
\hline sildenafil (sil) & $x$ & $\checkmark$ & isostructural & 22 & 0.601 & 0.010 & 0.982 \\
\hline theophylline $e^{* *}(\mathbf{t h p})$ & $\checkmark$ & $x$ & none & 2 & 0.800 & 0.014 & 0.891 \\
\hline
\end{tabular}

${ }^{a}$ Asterisked items: $(*)$ Root-mean-square deviation value for the overlay of the matched $N$ molecules in compared sac and tsac solids; $(* *)$ theophylline formed a nonsolvated cocrystal with saccharin and a nitromethane cocrystal solvate with thiosaccharin.
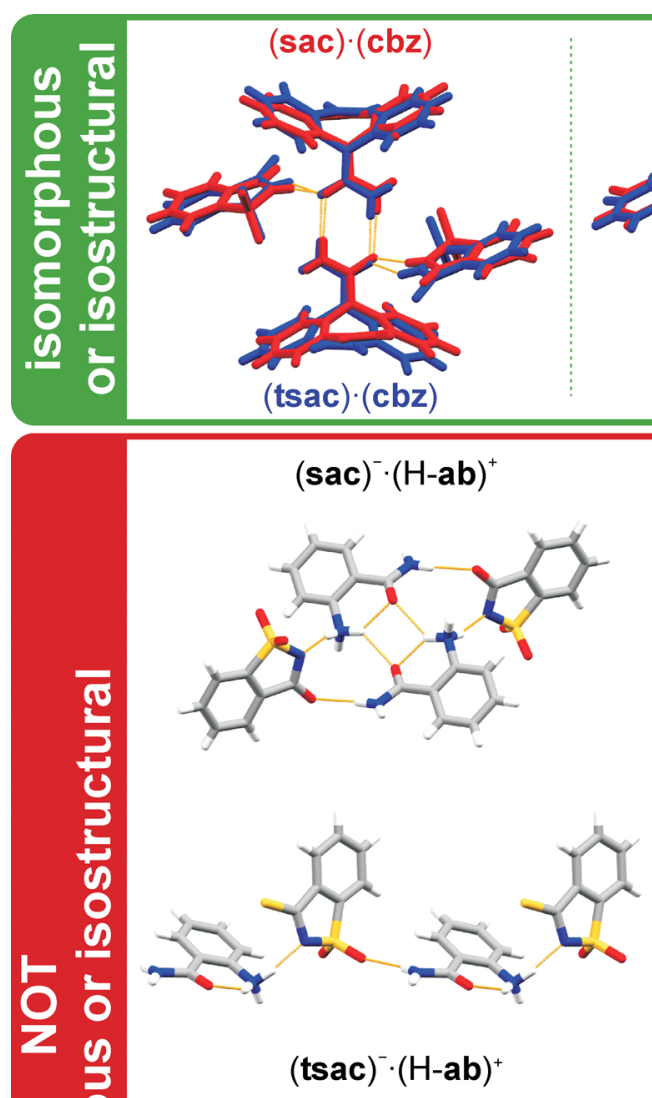

$(\text { sac })^{-} \cdot(\mathrm{H}-\text { hal })^{+}$form I

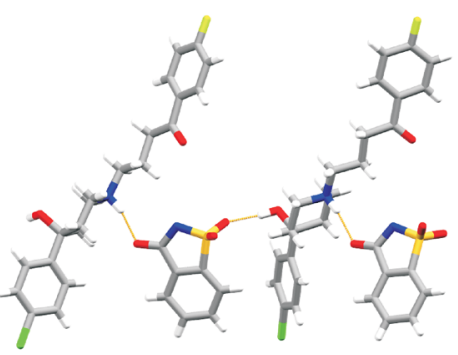

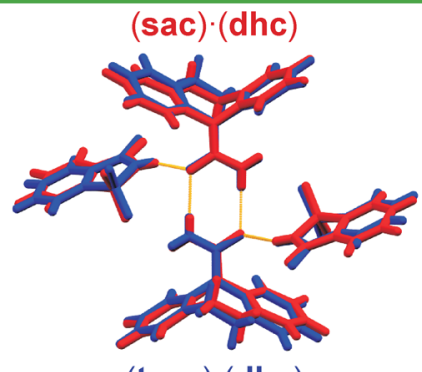

(tsac).(dhc)

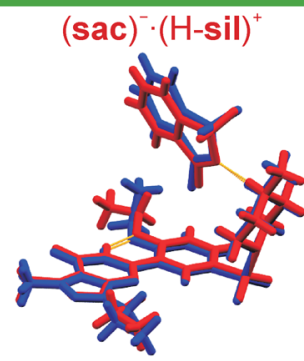

$(\text { tsac })^{-} \cdot(\mathrm{H}-\mathrm{sil})^{+}$

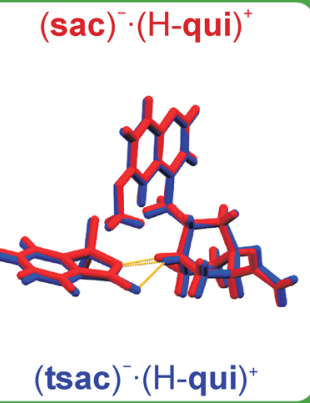

(sac)·(thp)
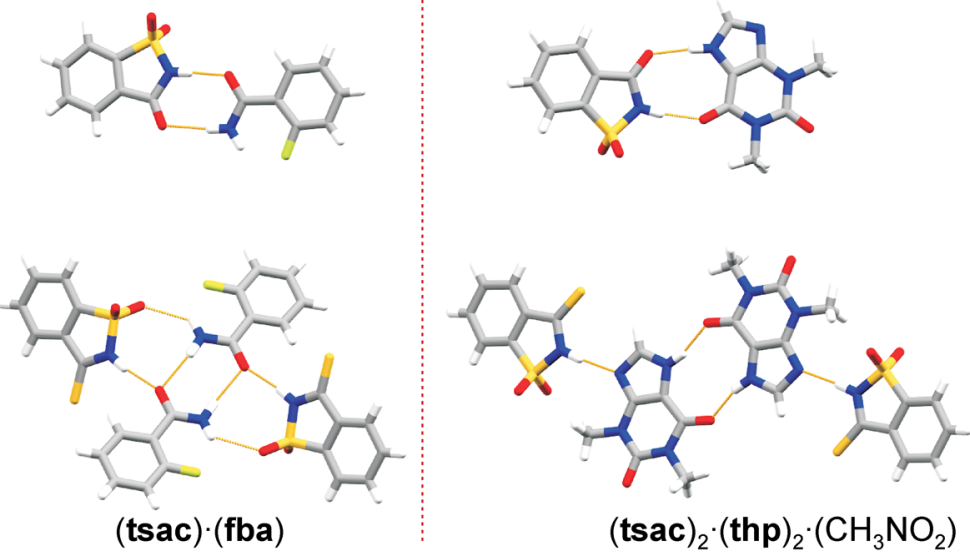

Figure 2. X-ray crystal structures of: isomorphous or isostructural or sac/tsac solids (top, highlighted in green), and structurally distinct sac/tsac solids (bottom, highlighted in red). 
the other hand, featured sac crystal structures that lacked the involvement of the $\mathrm{O}$ (carbonyl) of sac in intermolecular hydrogen bonding. These observations suggest that the size difference between oxygen and sulfur atoms (van der Waals radii, 152 and $180 \mathrm{pm}$, respectively ${ }^{71}$ ) does not limit the construction of isostructural and isomorphous solids through an $\mathrm{O} / \mathrm{S}$ atom exchange in molecular crystals. ${ }^{34}$ Indeed, a solid solution between barbituric acid and thiobarbituric acid has recently been reported. ${ }^{55}$ It was, thus, hypothesized that different electronic properties of $\mathrm{O}$ and $\mathrm{S}$ govern the formation of structurally distinct crystal architectures. Such postulation was subsequently corroborated through the calculation of electrostatic potential maps of sac and tsac (Figure 3) that
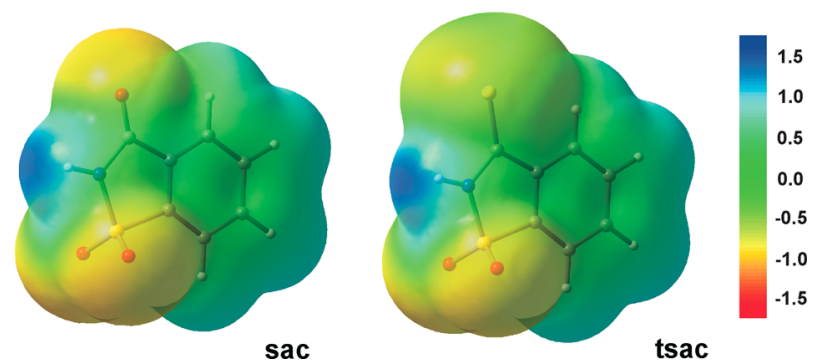

Figure 3. Electrostatic potentials maps of sac and tsac on an electron density isosurface highlighting a significant difference in the charge distribution around the carbonyl and thiocarbonyl groups of sac and tsac (an alternative view and details are in SI Figure S40). The scale runs from -1.76 (red) to $1.76 \mathrm{eV}$ (blue). highlighted the differences in potentials associated with the $\mathrm{O}$ and $S$ atoms of sac and tsac. The dominant difference is that the electrostatic potential around $\mathrm{C}=\mathrm{S}$ is much less stabilizing than around $\mathrm{C}=\mathrm{O}$, so leading to weaker and less directional $\mathrm{S} \cdots \mathrm{H}-$ $\mathrm{X}$ hydrogen bonds, as compared to $\mathrm{O} / \mathrm{N} \cdots \mathrm{H}-\mathrm{X}$ hydrogen bonds. $^{72}$ It is anticipated that replacing hydrogen-bonding $\mathrm{O}$ atoms with $S$ atoms renders resultant crystal lattices energetically less favorable.

To further explore the effect of the $\mathrm{O} / \mathrm{S}$ exchange (and the associated changes in charge distributions) on the construction of isostructural molecular crystals, we performed a computational study of sac and tsac crystal structures to evaluate changes in crystal lattice energies associated with an $\mathrm{O} /$ $\mathrm{S}$ (carbonyl) atom exchange in hydrogen-bonded sac/tsac crystal lattices.

Since only one polymorph of sac is known (CSD refcode SCCHRN, ${ }^{73}$ Figure $4 a$ ), we first focused on the identification of thermodynamically plausible crystal structures of sac that exhibit distinct hydrogen-bond patterns. Alternative crystal structures were generated by MOLPAK ${ }^{74}$ and lattice energy minimized by DMACRYS ${ }^{75}$ (see SI). Three low-energy sac structures displaying distinct and representative hydrogen-bond patterns were selected for detailed study (Figure 4a). These hypothetical and the experimental structures of sac were subjected to lattice energy optimization using periodic DFT-D (PBE+TS) (see SI). The SCCHRN structure was identified as the thermodynamically most stable form, while the other hypothetical sac structures with different hydrogen-bonding motifs were significantly higher in energy, (Figure $4 a$ ), which is consistent with no observation of sac polymorphs to date. ${ }^{76}$
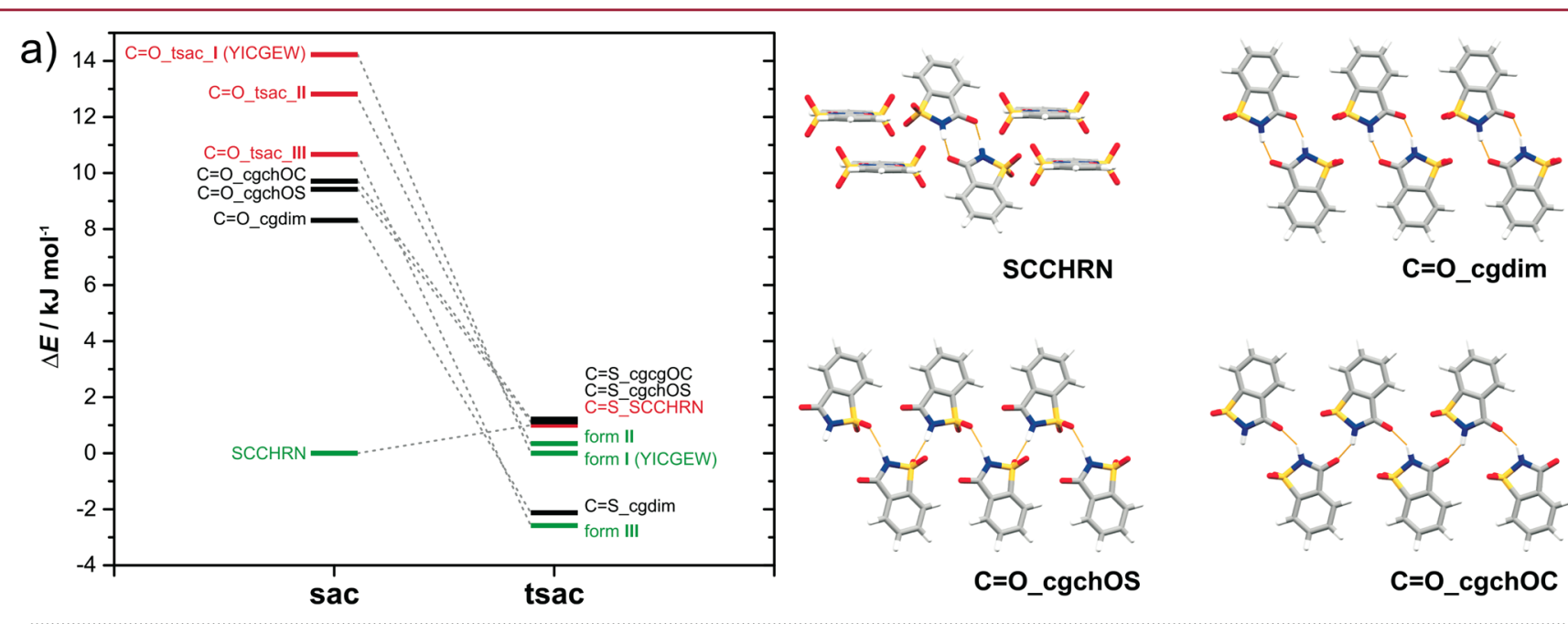

b)
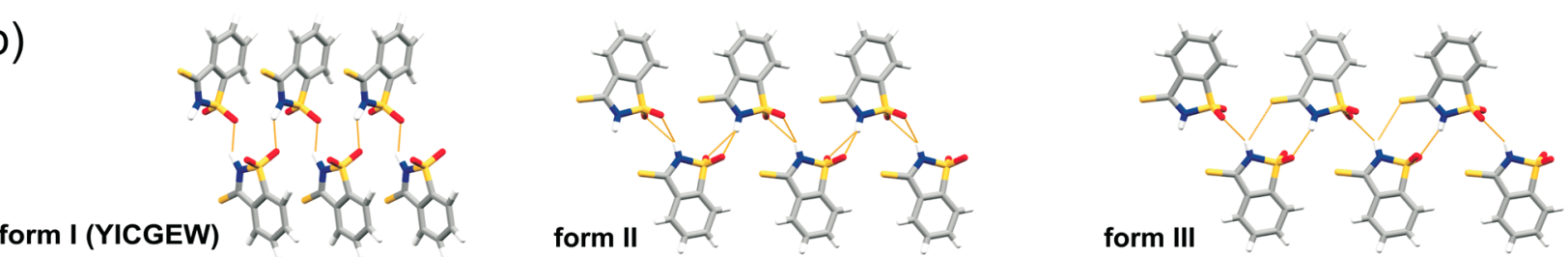

Figure 4. (a) Relative DFT-D lattice energies of the observed and hypothetical sac and tsac crystal structures (with a link between those related by $\mathrm{O} / \mathrm{S}$ atom exchange). The molecular assemblies shown on the right side represent the experimentally observed sac form (CSD refcode SCCHRN) and three computer-generated plausible crystal sac structures that exhibit distinct hydrogen-bond patterns. Colors of the structure labels in the graph: green, experimentally observed forms; red, computer-generated but experimentally unobserved O-/S-substituted versions of the experimental forms; black, additional computer-generated structures. (b) Experimentally observed tsac forms I (CSD refcode YICGEW), II, and III. The solids exhibit distinct hydrogen-bond patterns in accordance with a user-defined description of hydrogen bonds in the Mercury software. ${ }^{79}$ 
The next stage in the computational analysis involved an $\mathrm{O} /$ $\mathrm{S}$ (carbonyl) exchange in the sac crystal structures to generate hypothetical tsac crystal structures and an $\mathrm{O} / \mathrm{S}$ (thiocarbonyl) exchange in the only known structurally characterized tsac crystal form (form I, CSD refcode: YICGEW, ${ }^{77}$ Figure 4). The atom exchange causes a significant rearrangement in the energy ranking (Figure 4a). The relative tsac crystal energies (Figure 4a) clearly predicted that tsac was likely to be polymorphic. Notably, a subsequent polymorph screen (see SI) led to the discovery of a novel polymorph, tsac form II (Figure 4b).

It was then found that form II transformed on cooling into another new polymorph, namely, form III (Figure $4 b$ ), and on heating may have formed a further polymorph (as evidenced by a simultaneous PXRD-DSC study ${ }^{78}$ that revealed a change in the diffractograms in the $169-173{ }^{\circ} \mathrm{C}$ temperature range; see SI). Including the structures of tsac forms II and III in the $\mathrm{O} / \mathrm{S}$ exchange computational study, suggested that the new polymorphs of tsac were very close in energy to form I, but the corresponding sac crystal structures were sufficiently less stable than SCCHRN that they were unlikely to be observed.

Polymorphs II and III are very closely related $\left(\mathrm{RMSD}_{14}=\right.$ $0.38 \AA$ ) , and indeed are isostructural to the computer-generated structures on the molecular overlay criterion $(\mathrm{C}=\mathrm{S}$ _cgchOC has $\mathrm{RMSD}_{15}=0.58 \AA$ for form II and $\mathrm{C}=\mathrm{S} \operatorname{cgch} \mathrm{OS}$ has $\mathrm{RMSD}_{11}=0.62 \AA$ for form III). The polymorphs, however, display different hydrogen bonding ${ }^{79}$ whereby one $\mathrm{N}-\mathrm{H} \cdots \mathrm{O}=$ $\mathrm{S}$ hydrogen bond in form II is replaced by a $\mathrm{N}-\mathrm{H} \cdots \mathrm{S}=\mathrm{C}$ hydrogen bond in form III (Figure 4b). The computer modeling of the tsac structures shows that the proximity of the $\mathrm{C}=\mathrm{S} / \mathrm{O}, \mathrm{N}-\mathrm{H}$, and $\mathrm{SO}_{2}$ functional groups means that small shifts in structure move across the geometrical hydrogenbond criteria (see SI and Figure 4). Thus, in terms of molecular overlay similarity, computational $\mathrm{S} / \mathrm{O}$ substitution has predicted the existence of the novel tsac polymorphs.

Altogether, the results of the computational study clearly demonstrate that $\mathrm{O} / \mathrm{S}$ atom exchanges in the hydrogen-bonded crystals of sac and tsac significantly alter the relative lattice energies. This supports our hypothesis that differences in electronic properties and hence hydrogen-bonding strength and directionality between $\mathrm{C}=\mathrm{O}$ and $\mathrm{C}=\mathrm{S}$ prevent the formation of equivalent supramolecular structures which involve $\mathrm{N}-\mathrm{H} \cdots$ $\mathrm{O} / \mathrm{S}$ hydrogen bonding in the sac/tsac cocrystals.

\section{CONCLUSIONS}

A combined crystallographic and computational study of crystal forms of sac and tsac showed that replacement of the $\mathrm{O}$ (carbonyl) atom with a $\mathrm{S}$ atom leads to the formation of isostructural or isomorphous crystal forms in cases where the $\mathrm{O}$ (carbonyl) atom is not involved in hydrogen bonding. The sensitivity of the supramolecular structure to any hydrogen bonding to the $\mathrm{O} / \mathrm{S}$ atom was attributed to their different electrostatic properties (and hence hydrogen-bonding strength and directionality of the $\mathrm{C}=\mathrm{O}$ and $\mathrm{C}=\mathrm{S}$ groups), rather than to their steric differences.

It is noteworthy that our findings are consistent with those of a study of the $\mathrm{Cl} / \mathrm{CH}_{3}$ exchange principle that suggested that this exchange rule is less successful when "directional and/or electrostatic interactions are involved." ${ }^{\text {" }}$ Related cocrystal studies, on the other hand, have shown that isostructurality is maintained when halogen-bonded $\mathrm{Br}$ and $\mathrm{I}$ atoms are exchanged. ${ }^{80-82}$ These observations, along with our results, strongly suggest that Kitaigorodskii's proposition that "volume relationships are decisive in organic crystals, while the chemical natures of the atoms have little effect on the molecular interactions" ${ }^{34}$ is not universally applicable and that our understanding of how molecules pack into crystal lattices needs to be modified according to types of molecular interactions. We believe that deriving crystal-engineering guidelines that take into account both the chemical properties of functional groups and their environment in the crystal structure will significantly contribute to our ability to target specific crystal architectures and, thereby, prepare functional materials with desired properties.

Our findings start this process by providing guidelines for the formation of isostructural molecular crystals involving compounds based on $>\mathrm{C}=\mathrm{O}$ and $>\mathrm{C}=\mathrm{S}$ functional groups (i.e., only likely if the exchanged $\mathrm{O} / \mathrm{S}$ is not involved in hydrogen bonding). Current investigations in our research groups are focused on the structural equivalence of $\mathrm{O}$ and $\mathrm{S}$ atoms in molecular solids based on other $\mathrm{O}$-containing functional groups (e.g., amides and alcohols).

\section{ASSOCIATED CONTENT}

\section{S Supporting Information}

The Supporting Information is available free of charge on the ACS Publications website at DOI: 10.1021/acs.cgd.6b01669.

Details concerning the synthesis of sac and tsac crystal forms, polymorph screens, computational studies, and crystallographic, thermal, and spectroscopic analyses (PDF)

\section{Accession Codes}

CCDC 1484229-1484240 contains the supplementary crystallographic data for this paper. These data can be obtained free of charge via www.ccdc.cam.ac.uk/data request/cif, or by emailing data_request@ccdc.cam.ac.uk, or by contacting The Cambridge Crystallographic Data Centre, 12, Union Road, Cambridge CB2 1EZ, UK; fax: +44 1223336033.

\section{AUTHOR INFORMATION}

\section{Corresponding Author}

*E-mail: d.bucar@ucl.ac.uk.

ORCID

Simon Gaisford: 0000-0003-1000-3208

Dejan-Krešimir Bučar: 0000-0001-6393-276X

\section{Author Contributions}

${ }^{\S}$ M.K.C. and R.G. contributed equally to this work.

\section{Notes}

The authors declare no competing financial interest.

\section{ACKNOWLEDGMENTS}

Robert W. Lancaster, Rona Watson, Louise S. Price, and Alex Clout are acknowledged for their assistance throughout different stages of the study. M.K.C. and D.K.B. acknowledge the support of University College London through a UCL Excellence Fellowship. EPSRC is thanked for supporting the work through Grant EP/K03929/1. Periodic DFT-D calculations were performed on ARCHER, the U.K.'s national highperformance computing service, via our membership in the U.K.'s HPC Materials Chemistry Consortium, which is funded by EPSRC (Grant EP/L000202). ARCHER is funded by the Office of Science and Technology through EPSRC's High End Computing Programme. Diamond Light Source is thanked for access to beamline I12 (Grant EE-12735). 


\section{REFERENCES}

(1) Datta, S.; Grant, D. J. W. Nat. Rev. Drug Discovery 2004, 3, 4257.

(2) Developing Solid Oral Dosage Forms: Pharmaceutical Theory and Practice, 1st ed.; Qiu, Y., Zhang, G. G. Z., Chen, Y., Porter, W., Eds.; Academic Press: London, 2009.

(3) Mei, J.; Diao, Y.; Appleton, A. L.; Fang, L.; Bao, Z. J. Am. Chem. Soc. 2013, 135, 6724-6746.

(4) Henson, Z. B.; Mullen, K.; Bazan, G. C. Nat. Chem. 2012, 4, 699-704.

(5) Hao, Z.; Iqbal, A. Chem. Soc. Rev. 1997, 26, 203-213.

(6) Herbst, W.; Hunger, K. Industrial organic pigments, 3rd ed.; WileyVCH Verlag: Weinheim, Germany, 2004; DOI: 10.1002/3527602429. (7) Paul, S. M.; Mytelka, D. S.; Dunwiddie, C. T.; Persinger, C. C.; Munos, B. H.; Lindborg, S. R.; Schacht, A. L. Nat. Rev. Drug Discovery 2010, 9, 203-214.

(8) Steed, J. W. Trends Pharmacol. Sci. 2013, 34, 185-193.

(9) Schultheiss, N.; Newman, A. Cryst. Growth Des. 2009, 9, 29502967.

(10) Desiraju, G. R. J. Am. Chem. Soc. 2013, 135, 9952-9967.

(11) Aakeröy, C. B. Acta Crystallogr., Sect. B: Struct. Sci., Cryst. Eng. Mater. 2015, 71, 387-391.

(12) Perry, J. J., IV; Perman, J. A.; Zaworotko, M. J. Chem. Soc. Rev. 2009, 38, 1400-1417.

(13) Hoskins, B. F.; Robson, R. J. Am. Chem. Soc. 1989, 111, 59625964

(14) Furukawa, H.; Cordova, K. E.; O’Keeffe, M.; Yaghi, O. M. Science 2013, 341, 1230444.

(15) Kitagawa, S.; Kitaura, R.; Noro, S.-i. Angew. Chem., Int. Ed. 2004, 43, 2334-2375.

(16) Aakeröy, C. B.; Desper, J.; Fasulo, M.; Hussain, I.; Levin, B.; Schultheiss, N. CrystEngComm 2008, 10, 1816-1821.

(17) Corpinot, M. K.; Stratford, S. A.; Arhangelskis, M.; AnkaLufford, J.; Halasz, I.; Judaš, N.; Jones, W.; Bučar, D.-K. CrystEngComm 2016, 18, 5434-5439.

(18) Bučar, D.-K.; Lancaster, R. W.; Bernstein, J. Angew. Chem., Int. Ed. 2015, 54, 6972-6993.

(19) Groom, C. R.; Allen, F. H. Angew. Chem., Int. Ed. 2014, 53, 662-671.

(20) Price, S. L. Chem. Soc. Rev. 2014, 43, 2098-2111.

(21) Price, S. L.; Braun, D. E.; Reutzel-Edens, S. M. Chem. Commun. 2016, 52, 7065-7077.

(22) Day, G. M. Crystallogr. Rev. 2011, 17, 3-52.

(23) Bučar, D.-K.; Henry, R. F.; Zhang, G. G. Z.; MacGillivray, L. R. Cryst. Growth Des. 2014, 14, 5318-5328.

(24) Bučar, D.-K.; Henry, R. F.; Lou, X.; Duerst, R. W.; Borchardt, T. B.; MacGillivray, L. R.; Zhang, G. G. Z. Mol. Pharmaceutics 2007, 4, 339-346.

(25) Aakeröy, C. B.; Wijethunga, T. K.; Haj, M. A.; Desper, J.; Moore, C. CrystEngComm 2014, 16, 7218-7225.

(26) Kavuru, P.; Aboarayes, D.; Arora, K. K.; Clarke, H. D.; Kennedy, A.; Marshall, L.; Ong, T. T.; Perman, J.; Pujari, T.; Wojtas, Ł.; Zaworotko, M. J. Cryst. Growth Des. 2010, 10, 3568-3584.

(27) Bis, J. A.; Vishweshwar, P.; Weyna, D.; Zaworotko, M. J. Mol. Pharmaceutics 2007, 4, 401-416.

(28) Duggirala, N. K.; Wood, G. P. F.; Fischer, A.; Wojtas, Ł.; Perry, M. L.; Zaworotko, M. J. Cryst. Growth Des. 2015, 15, 4341-4354.

(29) Aakeröy, C. B.; Chopade, P. D.; Ganser, C.; Desper, J. Chem. Commun. 2011, 47, 4688-4690.

(30) Bučar, D.-K.; Day, G. M.; Halasz, I.; Zhang, G. G. Z.; Sander, J. R. G.; Reid, D. G.; MacGillivray, L. R.; Duer, M. J.; Jones, W. Chem. Sci. 2013, 4, 4417-4425.

(31) Jones, W.; Theocharis, C. R.; Thomas, J. M.; Desiraju, G. R. J. Chem. Soc., Chem. Commun. 1983, 1443-1444.

(32) Theocharis, C. R.; Desiraju, G. R.; Jones, W. J. Am. Chem. Soc. 1984, 106, 3606-3609.

(33) Bar, I.; Bernstein, J. Acta Crystallogr., Sect. B: Struct. Sci. 1983, 39, 266-272.
(34) Kitaigorodskii, A. I. Organic Chemical Crystallography. Consultants Bureau: New York, 1961; 541 pp.

(35) Edwards, M. R.; Jones, W.; Motherwell, W. D. S.; Shields, G. P. Mol. Cryst. Liq. Cryst. Sci. Technol., Sect. A 2001, 356, 337-353.

(36) Bar, I.; Bernstein, J. Tetrahedron 1987, 43, 1299-1305.

(37) Stanković, S.; Petrović, J.; Miljković, D.; Pejanović, V.; Kovačević, R.; Stefanović, A.; Bruvo, M. Acta Crystallogr., Sect. C: Cryst. Struct. Commun. 1992, 48, 1248-1252.

(38) Reddy, C. M.; Kirchner, M. T.; Gundakaram, R. C.; Padmanabhan, K. A.; Desiraju, G. R. Chem. - Eur. J. 2006, 12, 2222-2234.

(39) Sarma, B.; Nath, N. K.; Bhogala, B. R.; Nangia, A. Cryst. Growth Des. 2009, 9, 1546-1557.

(40) Bhogala, B. R.; Basavoju, S.; Nangia, A. CrystEngComm 2005, 7, 551-562.

(41) Aakeröy, C. B.; Sinha, A. S.; Epa, K. N.; Chopade, P. D.; Smith, M. M.; Desper, J. Cryst. Growth Des. 2013, 13, 2687-2695.

(42) Metrangolo, P.; Resnati, G. Chem. - Eur. J. 2001, 7, 2511-2519.

(43) Metrangolo, P.; Neukirch, H.; Pilati, T.; Resnati, G. Acc. Chem. Res. 2005, 38, 386-395.

(44) Aakeröy, C. B.; Wijethunga, T. K.; Desper, J.; Moore, C. J. Chem. Crystallogr. 2015, 45, 267-276.

(45) Kálmán, A.; Parkanyi, L.; Argay, G. Acta Crystallogr., Sect. B: Struct. Sci. 1993, 49, 1039-1049.

(46) "Two crystals are said to be isostructural if they have the same structure, but not necessarily the same cell dimensions nor the same chemical composition, and with a 'comparable' variability in the atomic coordinates to that of the cell dimensions and chemical composition." IUCR Online Dictionary of Crystallography, http://reference.iucr.org/ dictionary/Isostructural_crystals.

(47) "Two crystals are said to be isomorphous if (a) both have the same space group and unit-cell dimensions and (b) the types and the positions of atoms in both are the same except for a replacement of one or more atoms in one structure with different types of atoms in the other (diadochy), such as heavy atoms, or the presence of one or more additional atoms in one of them (isomorphous addition)." IUCR Online Dictionary of Crystallography, http://reference.iucr.org/ dictionary/Isomorphous crystals.

(48) Thomas, N. W.; Desiraju, C. R. Chem. Phys. Lett. 1984, 110, 99102

(49) Desiraju, G. R. Nature 2004, 431, 25-25.

(50) Desiraju, G. R.; Sarma, J. A. R. P. Proc. - Indian Acad. Sci., Chem. Sci. 1986, 96, 599-605.

(51) Bendikov, M.; Wudl, F.; Perepichka, D. F. Chem. Rev. 2004, 104, 4891-4946.

(52) Cao, J.; Zuo, C.; Du, B.; Qiu, X.; Ding, L. Chem. Commun. 2015, 51, 12122-12125.

(53) Patra, A.; Wijsboom, Y. H.; Leitus, G.; Bendikov, M. Chem. Mater. 2011, 23, 896-906.

(54) Sutton, C.; Risko, C.; Brédas, J.-L. Chem. Mater. 2016, 28, 3-16.

(55) Shemchuk, O.; Braga, D.; Grepioni, F. Chem. Commun. 2016, 52, 11815-11818.

(56) Kremer, A.; Aurisicchio, C.; De Leo, F.; Ventura, B.; Wouters, J.; Armaroli, N.; Barbieri, A.; Bonifazi, D. Chem. - Eur. J. 2015, 21, 15377-15387.

(57) Duhović, S.; Dincă, M. Chem. Mater. 2015, 27, 5487-5490.

(58) Zwijnenburg, M. A.; Corà, F.; Bell, R. G. J. Am. Chem. Soc. 2007, 129, 12588-12589.

(59) Kirby, I. L.; Pitak, M. B.; Wilson, C.; Gale, P. A.; Coles, S. J. CrystEngComm 2015, 17, 2815-2826.

(60) Groom, C. R.; Bruno, I. J.; Lightfoot, M. P.; Ward, S. C. Acta Crystallogr., Sect. B: Struct. Sci., Cryst. Eng. Mater. 2016, 72, 171-179.

(61) Fleischman, S. G.; Kuduva, S. S.; McMahon, J. A.; Moulton, B.; Bailey Walsh, R. D.; Rodríguez-Hornedo, N.; Zaworotko, M. J. Cryst. Growth Des. 2003, 3, 909-919.

(62) Oliveira, M. A.; Peterson, M. L.; Davey, R. J. Cryst. Growth Des. 2011, 11, 449-457.

(63) Bhatt, P. M.; Ravindra, N. V.; Banerjee, R.; Desiraju, G. R. Chem. Commun. 2005, 1073-1075. 
(64) Aitipamula, S.; Wong, A. B. H.; Chow, P. S.; Tan, R. B. H. Cryst. Growth Des. 2014, 14, 2542-2556.

(65) Banerjee, R.; Bhatt, P. M.; Desiraju, G. R. Cryst. Growth Des. 2006, 6, 1468-1478.

(66) Lu, E.; Rodriguez-Hornedo, N.; Suryanarayanan, R. CrystEngComm 2008, 10, 665-668.

(67) Chisholm, J. A.; Motherwell, S. J. Appl. Crystallogr. 2005, 38, $228-231$.

(68) Macrae, C. F.; Bruno, I. J.; Chisholm, J. A.; Edgington, P. R.; McCabe, P.; Pidcock, E.; Rodriguez-Monge, L.; Taylor, R.; van de Streek, J.; Wood, P. A. J. Appl. Crystallogr. 2008, 41, 466-470.

(69) Several other numerical descriptors have been developed to quantify the degree of similarity of two solids. For more details see: (a) Kálmán, A.; Argay, G.; Scharfenberg-Pfeiffer, D.; Höhne, E.; Ribár, B. Acta Crystallogr., Sect. B: Struct. Sci. 1991, 47, 68-77. (b) FáBian, L.; Kálmán, A. Acta Crystallogr., Sect. B: Struct. Sci. 1999, 55, 1099-1108.

(70) Wood, P. A.; Oliveira, M. A.; Zink, A.; Hickey, M. B. CrystEngComm 2012, 14, 2413-2421.

(71) Bondi, A. J. Phys. Chem. 1964, 68, 441-451.

(72) Krepps, M. K.; Parkin, S.; Atwood, D. A. Cryst. Growth Des. 2001, 1, 291-297.

(73) Bart, J. C. J. J. Chem. Soc. B 1968, 376-382.

(74) Holden, J. R.; Du, Z.; Ammon, H. L. J. Comput. Chem. 1993, 14, $422-437$.

(75) Price, S. L.; Leslie, M.; Welch, G. W. A.; Habgood, M.; Price, L. S.; Karamertzanis, P. G.; Day, G. M. Phys. Chem. Chem. Phys. 2010, 12, 8478-8490.

(76) Price, S. L. Acta Crystallogr., Sect. B: Struct. Sci., Cryst. Eng. Mater. 2013, 69, 313-328.

(77) Grupče, O.; Penavić, M.; Jovanovski, G. J. Chem. Crystallogr. 1994, 24, 581-586.

(78) Clout, A.; Buanz, A. B. M.; Prior, T. J.; Reinhard, C.; Wu, Y.; O'Hare, D.; Williams, G. R.; Gaisford, S. Anal. Chem. 2016, 88, 10111-10117.

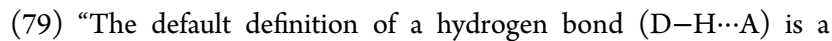
contact meeting the following criteria: 1) the donor (D) must be a nitrogen, oxygen or sulfur atom covalently bound to at least one hydrogen, 2) the acceptor (A) must be a nitrogen, oxygen, sulfur or halogen with at least one available lone pair (e.g., pyramidal trigonal nitrogen is regarded as an acceptor but planar trigonal nitrogen is not),

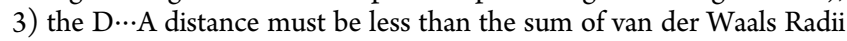
of the D and A atoms; 4) the contact may be intermolecular, or intramolecular involving donor and acceptor atoms separated by at least 3 covalent bonds within the molecule." (Mercury CSD 3.8). The user-defined classification of a hydrogen bond applied in this study involves the recommended atom-atom contact range (viz., a maximal distance that equals the sum of the van der Waals radii) and a $\mathrm{D}-\mathrm{H} \cdots$ A angle requirement of $\geq 120^{\circ}$ (default value). Mercury User Guide and Tutorials, 2016 CSDS Release; Cambridge Crystallographic Data Centre: Cambridge, U.K., 2015.

(80) Cinčić, D.; Friščić, T.; Jones, W. New J. Chem. 2008, 32, 17761781.

(81) Cinčić, D.; Friščić, T.; Jones, W. Chem. - Eur. J. 2008, 14, 747753.

(82) Cinčić, D.; Friščić, T.; Jones, W. Chem. Mater. 2008, 20, 66236626. 